\title{
Evaluation of Two Assessment Techniques for Adaptation to Stress
}

\author{
Janet S. Barnfather, RN; PHD* \\ Mary ANn Price SwaIn, RN; PHD* \\ HeLEN C. ERICKSON, RN; PhD†
}

\begin{abstract}
Two conceptual nursing models, Roy's adaptation model and Erickson and Swain's adaptive potential assessment model are explained, and knowledge is identified within these two assessment techniques for adaptation to stress. The purpose is to identify common, noteworthy areas of nursing science as well as areas where further development in nursing knowledge is needed. A case study is used to compare and contrast these models. When assessing adaptation to stress, one similarity between the approaches appears to be a propositional linkage that supports the influence of developmental level on basic need satisfaction. A divergent area between the two models identifies a need for further development in nursing knowledge regarding the adaptive potential status. This includes information pertaining to what an individual can reasonably do or be expected to do when contending with stressors.
\end{abstract}

Models are useful in organizing knowledge. Conceptual models are useful in developing the science of nursing. Whall (1989) addresses some important considerations about models which include the following points. The term "conceptual model" is used in disciplines related to nursing such as family sociology and life span development psychology. The word conceptual is an adjective that modifies model. There are models of various types including those made of clay and wood. A model constructed of concepts is a conceptual model. Models are useful in identifying knowledge and for comparison, to better understand the structure of the knowledge. In this presentation two conceptual nursing models, Roy's adaptation model (Andrews \& Roy, 1986; Roy, 1984) and the adaptive potential assessment model (Erickson, 1976; Erickson \& Swain, 1982) are explained, and knowledge is identified within the two approaches. A case study

Key Words: Adaptation to Stress, Roy's Model, Modeling and Role-Modeling, Assessment of Adaptive Potential

Recelved September 27, 1988.

Accepted November 3, 1988.

- University of Michigan School of Nursing. Ann Arbor, MI.

+ University of Texas at Austin, Austin, TX.

This study was supported in part by a National Research Service Award, Predoctoral Nurse Fellowship, grant 5F31 NU-05657-03.

0894-3184/89/0204-172\$02.00/0

Nursing Science Guarterly

Copyright $\odot$ by Williams \& Wilkins is used to compare and contrast these models, and judgments about the two assessment techniques are explored to highlight noteworthy areas in nursing science. The focus is on examination of two assessment techniques regarding adaptation to stress. Concurring and diverging parts of the two models are identified and point to a need for further development in the nursing knowledge.

Definition of terms are compared from each model. Sound theoretical views of stressors and stress (Lyon \& Werner, 1987) are evident in each approach. Stressors are described as stimuli that precede and elicit stress and stress is a nonspecific, holistic response to any stimuli (Erickson, Tomlin, \& Swain, 1988). Roy (1984) provides a similar definition by stating that stressors are influencing stimuli resulting in the stress response which is viewed in terms of behavioral manifestations or resulting problems. Erickson and Swain (1982) make the distinction between stressor and distressor, using appraisal theory (Lazarus, 1966). A stressor is viewed as a challenge, and a distressor is viewed as a threat to the individual. Roy (1984) and Andrews and Roy (1986) cite examples that implicitly agree with this approach. A specific example includes the challenge of learning to drive a car and the threat of an accident while driving (Andrews \& Roy, 1986, p. 40). The theoretical distinction for the terms threat and challenge are not specifically addressed in Roy's adaptation model. Further agreement includes the view of human beings. Individuals are viewed in both 
models as having biopsychosocial subsystems in which dynamic interaction occurs.

The authors define the following terms in unique ways. Roy (1984) defines coping mechanisms as cognator and regulator activities which are acquired or innate ways of responding to the changing environment. The cognator subsystem responds through complex processes of perception and information processing, learning, judgment, and emotion. The regulator subsystem responds automatically through neural-chemical-endocrine processes. Environment includes internal or external stimuli or all conditions, circumstances and influences surrounding and/or affecting the development, and behavior of persons or groups. Adaptive responses promote integrity of the person in terms of the goals of survival, growth, reproduction, and mastery. Ineffective responses do not contribute to adaptive goals. And health is a state and a process of being and becoming an integrated and whole (holistic) person. Erickson, Tomlin, and Swain (1988) define coping as the process of contending with stressors and can be adaptive (health and growth directed) or maladaptive (illness directed). A maladaptive response involves one subsystem being taxed, and perhaps depleted, in an attempt to support another. Adaptive and maladaptive coping responses are considered to be holistic, which means individuals are more than the sum of their biophysical, psychological, sociological, and spiritual subsystems. Health is a state of physical, mental, and social well-being, not merely the absence of disease or infirmity (WHO, 1988) and assumes a balance among the subsystems.

Since the focus in this presentation is limited to examination of two models as assessment techniques for adaptation to stress, neither model is thoroughly represented; and only a brief overview of each model is presented. The adaptive potential assessment model (APAM) is part of a multidimensional assessment strategy used by nurses in the implementation of the theory entitled "modeling and role-modeling" (Erickson, Tomlin, \& Swain, 1988). The APAM has three main states: arousal, equilibrium, and impoverishment with each state representing a different potenial to mobilize coping resources. Arousal and impoverishment are considered stress states whereas equilibrium is considered a nonstress state. Theoretically, persons in equilibrium are building resources needed to contend with stressors and have the best potential for mobilizing coping resources. Individuals in the stress state of arousal have recently experienced stressors and are therefore mobilizing resources to contend with those stressors. Individuals in the stress state of impoverishment have experienced extensive or prolonged stressors and as a result have diminished, if not depleted, resources needed to contend with those stressors. Thus, individuals in impoverishment are at even greater risk when they are confronted with new stressors or are forced to contend further with ongoing stressors.

The APAM was developed by Erickson (1976) who synthesized the physiological stress theory of Selye (1976) and the psychosocial theory of Engel $(1962,1968)$ into a single model to characterize certain mind-body relationships. Although Selye and Engel had proposed models of coping, each had proposed a model that considered only single subsystems of the person. Furthermore, these authors had proposed models that specified various stages of stress. The distinction of Erickson's approach was in considering all subsystems of the person and in identifying states of coping that would reflect the individual's ability to mobilize coping resources. Erickson (1976) and Erickson and Swain (1982) reasoned that Selye's alarm reaction seemed like Engel's fight-flight and Selye's exhaustion stage was close to Engel's conservation-withdrawal response. In addition, another theorist, Seligman (1975), who studied the helplessness-hopelessness syndrome seemed to be in agreement with Selye's exhaustion stage and Engel's conservative-withdrawal response. Erickson (1976) and Erickson and Swain (1982) renamed these aggregate stress states as arousal and impoverishment, respectively.

Theoretical underpinnings for the APAM include the fight-flight reaction that is characterized by increased motor behavior and increased verbalization which is often assertive or aggressive in nature. The differential activation of neuroendocrine systems includes sympathetic, adrenal-medullary, and catecholamine responses. Conversely, the conservative-withdrawal response is characterized by decreased motor behavior, decreased verbalization and apparent introversion. In addition, the APAM includes an appraisal component (Lazarus, 1966). A stressor can be perceived as a challenge or a threat. If a stressor is experienced as challenging, then there is potential to achieve healthier states and growth for the individual. Adaptive energy is available to contend with the stressor. However, when a stressor is experienced as threatening, then the response is potentially depleting or diminishing the store of energy. In the case of a threatening stressor, a new term, distressor, describes the stimulus which mounts a maladaptive response when one subsystem is overtaxed by another and the former becomes depleted and contributes little to mobilizing coping resources for the individual. Indicators for classification of individuals into one APAM state or another are based on the theoretical underpinnings and include tenseness/anxiousness, sadness/depression, fa- 
tigue, motor-sensory behavior, autonomic responses, and verbal anxiety. Furthermore, it is the patterning of these variables that determines an individual's APAM state (Barnfather, Swain \& Erickson, 1989; Barnfather, 1987; Erickson, 1976; Erickson \& Swain. 1982). The APAM was developed to provide a means of assessing an individual's ability to mobilize coping resources at any moment in time-that is, a state of coping.

The reliability of the APAM depends, in part, upon its linkage with the other concepts in the modeling and role-modeling theory and paradigm. These include understanding concepts drawn from the theoretical work of othersbasic and growth needs (Maslow, 1968, 1970); psychosocial development (Erickson, 1963, 1982); cognitive development (Piaget \& Inhelder, 1969) and object relations (Bowlby, 1981; Brody, 1980; Mahler, 1967; Winnicott, 1965). Theoretical propositions linking the APAM with concepts derived from all of the above theorists appear in other works (Barnfather, 1987; Erickson, Tomlin \& Swain, 1983; Ozbolt, 1987; Stein, 1989). Erickson (1976) believed that a model which identified the individual's ability to mobilize coping resources would provide a base for nurses to plan interventions and clients would benefit from receiving nursing care more appropriately tailored to their particular needs and adaptive capacities. Results from a study conducted in a hospital setting demonstrated that the three APAM states are valid, can be reliably identified in medical-surgical patients (Erickson, 1976) and predict patients' length of stay (Erickson \& Swain, 1982). Furthermore, construct validity was supported in healthy individuals (Barnfather, 1987). The modeling and role-modeling paradigm includes several specific intervention goals as well as related aims of intervention.

The Roy adaptation model (Andrews \& Roy, 1986; Roy, 1984) also contains goals of nursing that facilitate working with persons as adaptive systems contending with stressors. Roy (1984) values the humanistic base of her nursing model noting that the nurse is concerned about the person's psychological, spiritual, social, and physical health. Mind-body relationships are characterized by the cognator and regulator coping mechanisms through which all stimuli are processed (Roy, 1984; Roy \& Roberts, 1981). The regulator processes internal and external stimuli through neuralchemical-endocrine channels to produce responses. The other major adaptive coping mechanism is the cognator, which processes internal and external stimuli that involve psychosocial and physiological stimuli, including output of the regulator mechanism. These two mechanisms are explained and elaborated upon elsewhere (Andrews \& Roy, 1986; Roy,
1984; Roy \& Roberts, 1981). The theoretical work on the cognator and regulator processes is still in the beginning stages, and it is proposed that complex relationships between cognator and regulator processes can lead to further understanding of the holistic nature of humans (Andrews \& Roy 1986; Roy, 1984). Moreover, it is hypothesized that interactions between the cognator and regulator are mediated by perception, a function of the cognator; but how the actual transformation of bidirectional information flows between these two coping mechanisms is still unknown (Roy, 1984; Roy \& Roberts, 1981).

The cognator and regulator each act in relation to four effector modes: physiologic, selfconcept, role function, and interdependence. Observations of a large number of individuals in many health care situations (Roy, 1971) resulted in classifying observable behavior into these four categories. Each individual has a unique adaptation level which constantly changes representing the person's own standard range of stimuli that can be tolerated with ordinary efforts. As a result of this unique adaptation level, adaptive and ineffective behaviors are manifested by individuals in each of the four major effector modes. Several classes of stimuli interact to determine the adaptation level of an individual (Roy \& Roberts, 1981). The stimuli are defined (Roy, 1984) in the following ways: (a) focal stimuli or the'stimuli immediately confronting the person and the one that precipitates the behavior; (b) contextual stimuli, or all other stimuli present that contribute to the behavior precipitated by the focal stimuli; (c) residual stimuli, such as beliefs, attitudes, or traits which have an indeterminate effect on the present situation. The pooled effect of these three stimuli are considered within each of the four major effector modes and determines the individual's adaptive level.

Many theorists guided Roy (1984) in the development of the Roy adaptation model. The following theorists are highlighted by presenting brief examples for each adaptive mode. Selye $(1963,1976)$ has influenced the physiological mode of adaptation in the model. All components of the physiological mode may be affected by Selye's "general adaptation syndrome" in response to a stressor. These components include oxygenation, nutrition, elimination, activity and rest, skin integrity, the senses, fluid and electrolytes, and neurological and endocrine functions (Roy, 1984). Rolefunction draws from works of Goffman (1961) and Parsons and Shils (1951) who provide support for the importance of societal expectations and instrumental and expressive behaviors. Interdependence relies on Fromm (1956) and Havighurst (1953) for work pertaining to stimuli that influence interdependence behav- 
iors. The self-concept mode has been influenced by several social interaction theorists such as Mead (1934), and Sullivan (1953) as they expanded upon the work of Cooley (1902) who theorized that interaction with others helps to control and alter one's self appraisal through the concepts of "the looking-glass self" (Epstein, 1973). Other theorists include Coombs and Snygg (1959) who describe a perceptual approach about self-concept that includes oneself and one's own abilities and Gardner (1964) who proposed physical selfdevelopment, personal self-development, and learning to live with others (which is relevant to the role function and interdependence modes presented later). In addition, the Roy adaptation model relies upon Erikson (1963), a developmental theorist, to identify developmental stage and corresponding tasks to master, which is useful information in all four modes. In addition, Maslow's hierarchy of needs (1970) were compared to all four adaptive modes and the two approaches were found to have similarities (Roy, 1984). Recently, references to basic needs appear as the terms physiological integrity, psychic integrity, affectional adequacy, and social integrity (Andrews \& Roy, 1986).

The Roy adaptation model has been implemented in a variety of settings with promising results for nursing practice. Comprehensive lists appear elsewhere (Roy, 1984, 1988). Several projects from these lists include: a field study in episodic and distributive practice settings (Wagner, 1976); an example where a nurse used the model with young hospitalized children (Galligan, 1979); descriptions of implementation of the adaptation model with numerous clients of various age groups who are located along the wellness-illness continuum (Randell, Tedrow, \& Van Landingham, 1982); and a demonstration project in orthopedic and rehabilitation settings, which revealed improved patient care outcomes and enhanced professional nursing practice (Mastal \& Hammond, 1980; Mastal, Hammond, \& Roberts, 1982).

\section{Case Study}

Steve was a 19-year-old student at a large midwest university in the second half of his sophomore year. He was interviewed during midterm examination time, and had already taken an exam on that day. He reported that he believed he did poorly on the exam and felt anxious about another midterm in 2 days. Since leaving the exam, Steve had been feeling a little faintness, had a lot of gas (eructation), and had been having to urinate frequently. All other neurological, gastrointestinal, and genitourinary signs and symptoms were negative. Steve had no history of any major illness or accident. He had mild-moderate acne with a few comedones but there were too many present to actually count without a purposeful examination. His vital signs were $114 / 68$, radial pulse 57 , respirations 14 , and his weight was stable and wellproportioned for his height of $5 \mathrm{ft} 10 \mathrm{in}$. Appetite, fluid intake, and eating patterns were adequate and unchanged. In the past, Steve had jogged approximately $4 \mathrm{mi}$ several times a week, but reported that lately he ran only one day every 1-2 weeks for fewer than $4 \mathrm{mi}$. Usually Steve sleeps 7-8 hours every night, but he had been sleeping about 9 hours every night without feeling refreshed upon arising.

Steve was very interested in a political-social organization on campus and had been assigned the job of canvassing local neighborhoods to collect donations and contributions for the organization. He stated "I'm not doing so well. . . . I'm not forceful with my arguments. ... I'm just not bold with my statements. There's a quota to meet in three weeks and I haven't met mine, which is really bad for me and the group." Steve stated he took the last week or two off to try and think about "it all." He enjoyed and respected his friends in this group saying, "We get together every Wednesday night and go out for pizza and beer and have a really good time. They are all real people and they enjoy being with me as well."

Steve described his future in the following way. "I think I'm going to take off school next year, maybe work in Montana this summer or in California, and then go over to Europe for a year or so. Check that out and see how it goes. And then I'd like to come back here to school, but it's not for sure. I'm actually, at this point, pretty down on school. I'm just ground into the ground. I'm sick of studying and sick of examinations and things like that." Steve went on to say that he had a lot of trouble motivating himself. He had previously thought of himself as an excellent student who had been studying science, mostly physics and astronomy, but he had come to think that there was too much math and theory involved, adding "I don't see any practical use for it." Although he seemed very unsure, majoring in English was one possible area that Steve suggested might be useful for his future. As he talked, Steve sat very still, with shoulders flexed forward, not smiling, frowning, or using other facial expressions or body animation; and eye contact was infrequent after which he focused downward.

Steve's family consisted of parents and an older sister, Jennifer, who attended the same university as Steve. At the end of her freshman year Steve's sister had applied for and was accepted into a study-exchange program in Europe. Jennifer was an outstanding student and had received many honors and awards. Steve's father attended the same midwestern university and expected his children to graduate from this university. Total family income was about $\$ 80,000 /$ year indicating socioeconomic status of upper middle class. Steve's mother was a homemaker and involved in community services. Steve viewed his parents as supportive, loving, and interested in his welfare. Steve mentioned that he and his sister had frequent dis- 
cussions about their situations. Jennifer had indicated that she suspected their parents may be considering a trial separation.

\section{Assessment Models}

\section{The Roy Adaptation Model}

The Roy adaptation model (Andrews \& Roy, 1986; Roy, 1984) of assessing behavior involves a sequential process of examining cognator and regulator activities in each adaptive mode identified as physiological, self-concept, role performance, and interdependence. Firstlevel assessment occurs when the nurse systematically examines behavior in each adaptive mode by means of interview and observational skills in order to obtain measurement of internal and external client responses to environmental changes that require further adaptive responses and to gain subjective reports about the adaptive responses. The nurse determines, in collaboration with the person, whether behavior is adaptive or ineffective. The next step in the assessment process, second-level assessment, involves further assessment of the adaptive modes for those behaviors of concern identified in first-level assessment. Second-level assessment is not limited to ineffective adaptation or behaviors of concern, because the nurse and/or client may want to consider primary prevention strategies. At this point, or earlier if necessary, priorities are set for second-level assessment. Priority is defined as an order of urgency. Roy (1984) proposes the following hierarchy for individuals, families, groups, or communities. The categories include situations that: (a) threaten survival; (b) affect growth; (3) affect continuation of the human race or of society; and (d) affect attainment of full potential. Second-level assessment means looking for influencing factors on behavior previously described as focal, contextual, and residual stimuli (Andrews \& Roy, 1986; Roy, 1984). After first- and second-level assessment is complete, nursing diagnoses are made. Assessment data for Steve is described below.

\section{Role performance mode}

Roy (1984) states that "One of the first steps in doing the first-and second-level assessment in all four adaptive modes is to identify the person's age and stage of development" (p. 265). The Roy adaptation model refers the reader to Erikson (1963), although it is possible to draw upon other developmental theorists. Role-function includes the primary role which considers age, sex, and developmental stage. Therefore, it is important to identify Steve's primary role as that of a 19-year-old who is in late adolescentearly adulthood. The data suggest Steve was dealing with the conflict of identity versus role diffusion associated with the adolescent task to know "who I am." The secondary roles, those assumed to complete this developmental task. include student, son, and brother roles. Steve's tertiary role, freely chosen and temporary, was that of political-social group member; but since it probably contributed to role mastery, the tertiary role may also be considered as a secondary role. In adolescence, peer groups are especially important in shaping values and in relating to society. Steve was ineffective in his student role when he stated, "I'm actually, at this point, pretty down on school. ... I think I'm going to take off school next year. ... it's not for sure." The instrumental behaviors to accomplish the goal of graduation were weak. The expressive role performance behaviors included feelings of dislike for the student role. Steve ranked his role as student lowest, group member in the political-social organization highest, with son and brother in between. Cognator/regulator processes seemed to be especially ineffective in goal attainment associated with his role of student. Data supporting the basic need of social integrity (Andrews \& Roy, 1986) were scant, if not absent.

\section{Physiological mode}

First-level assessment for physical adaptation revealed several areas of concern. There was a slightly elevated pulse pressure of $46 \mathrm{mmHg}$. Bradycardia was present which may have been related to jogging. Rest/sleep/activity patterns were altered to the point that activity was reduced and sleep was increased without feelings of being refreshed. Steve mentioned there was too much work to do so that jogging had become difficult. Posture was poor as his anatomical alignment of shoulders and trunk were flexed forward. Skin was warm, dry and pink; and facial skin had acne with comedones. Eructation and frequency of urination had occurred only in the past few hours since the end of the midterm exam, and there was no accompanying nausea, vomiting or diarrhea, or increased thirst. Faintness began after leaving the examination whereas other neurological signs and symptoms such as confusion, disorientation, dizziness, pain, numbness, tingling, and inappropriate or limitation of movement were negative. Cognator/regulator processes were, for the most part, maintaining physiological functioning. The five basic needs of oxygenation, nutrition, elimination, activity and rest. and protection were judged as not threatening survival, although growth and achievement of potential were possible concerns.

\section{Self-concept mode}

First-level assessment for self-concept included the following areas of concern. Under personal self is the concept self-consistency, how one views oneself in relation to actual performance. Steve mentioned he was not forceful or bold 
enough, and he viewed his actual performance as inadequate. Furthermore, he believed his inadequacy was found in more than one role both as student and as a member of a peer group. Self-expectancy (ideal self) seemed to include trying to improve his behavior so that it was consistent with his peer group expectations. It was not clear that he intended to improve his behavior in order to master his science studies. Instead he saw himself leaving the sciences and perhaps eventually becoming more involved with English studies. He was very unsure of his educational goals. The content of his verbal communication, posture, tone of voice, and eye contact suggested ambivalence and discouragement. Steve's moral-ethical-spiritual self appeared shaky. Steve believed he should be more motivated about school to meet his father's expectations, but he felt "ground into the ground" and sick of studying. In the past, he had thought of himself. as an excellent student and as a likeable person who tried to do the right thing in a given situation. Cognator/regulator processes were ineffective in this mode. The basic need identified as psychic integrity (Andrews \& Roy, 1986) was shattered leaving no sense of unity.

\section{Interdependence mode}

Steve believed Jennifer was a very important person in his life. Each had assumed a contributive and receptive role in their relationship regarding nurturing behaviors and meeting human needs (Roy, 1984). His peer group had been another major source of social support. Since Steve had yet to meet his quota and the deadline was approaching. he was less confident in continued peer acceptance. Steve stated he did not know whether or not his parents would separate. He wished he could tell his parents that he loved them. Cognator/regulator processes seem adaptive but identification of potential areas of concern should be necessary. Evidence of the basic need of affectional adequacy (Andrews \& Roy, 1986) was present regarding Jennifer but uncertain for his parents.

Behaviors of concern appeared in all four adaptive modes. In general, the physiological mode had many more adaptive responses than ineffective responses. Survival concerns were not as apparent as they were with self-concept. role-function and to a lesser extent interdependence modes. A decision was made by the nurse to track first-level physical assessment data for Steve instead of moving to second-level assessment. Person-systems (Andrews \& Roy, 1986; Roy, 1984) have holistic responses among all four effector modes as dynamic interaction occurs. It is possible to observe changes in the physiological mode as feedback from all four modes is reprocessed by the cognator and regulator. Thus, first-level assessment should be tracked over time to determine whether or not second-level assessment is necessary. Interdependence had adequate adaptive responses with at least one individual, Jennifer, but past adaptive responses with parents were not entirely known. Although interdependence seemed somewhat adequate, further assessment may have prevented possible ineffective responses. Self-concept and role performance seemed to have few, if any, adaptive responses especially for growth and mastery. Survival of Steve's student role and accompanying growth were at risk as he dealt with the adolescent conflict of identity. The cognator/regulator processes in the self-concept and role performance modes resulted in ineffective responses. Thus, second-level assessment was carried out to show focal, contextual and residual stimuli in the self-concept (Table 1), role performance (Table 2), and interdependence (Table 3) modes. In the above tables, second-level assessment was examined for within mode responses to influencing stimuli. An additional point of interest was that the between mode relationships reflected Steve's developmental status. An example which relates developmental status to between mode relationships is included in the following explanation. Inherent in Steve's developmental stage of identity versus role diffusion were several crises and necessary decisions about self-concept, role performance, and intense peer group interdependence. Steve was trying to establish his identity in the competitive setting of a leading university which expects the highest academic quality of its students. Social development was through Steve's

Table 1

Secondary Assessment

\begin{tabular}{|c|c|}
\hline Self-Concept Mode & Influencing Stimuli \\
\hline $\begin{array}{l}\text { Self-consistency } \\
\text { I have trouble motivating myself. } \\
\text { Ideal-self } \\
\text { Perhaps I'll be an English major to achieve my ca- } \\
\text { reer goals. It is more practical than the sciences } \\
\text { of physics and astronomy. } \\
\text { Moral-ethical-spiritual } \\
\text { I'm ground into the ground. }\end{array}$ & $\begin{array}{l}\text { Focal: Has been an excellent student in the past. } \\
\text { Midterm exams may reveal poor grades. } \\
\text { Contextual: Developmental level of identity ver- } \\
\text { sus role diffusion. Dealing with "who I will be } \\
\text { and who I have been." Raised in an upper } \\
\text { middle class family that has valued successful } \\
\text { performance. Has been spending more time } \\
\text { with peers and less time on studies. } \\
\text { Residual: In the past, had successful perform- } \\
\text { ance been associated with acceptance as an } \\
\text { individual? Explore previous experience with } \\
\text { meeting self-ideals and expectations. }\end{array}$ \\
\hline
\end{tabular}


Table 2

Secondary Assessment

\begin{tabular}{|c|c|}
\hline Role Performance Mode & Influencing Stimuli \\
\hline $\begin{array}{l}\text { Student } \\
\text { I think I'm going to take off school next year. } \\
\text { Peer group } \\
\text { They are real people. They are my friends. } \\
\text { I'm not bold or forceful with my statements } \\
\text { when asking for donations. There is a quota } \\
\text { to meet in } 3 \text { weeks, and I haven't met mine, } \\
\text { which is really bad for me and the group. }\end{array}$ & $\begin{array}{l}\text { Focal: Midterm exams may indicate poor performance. } \\
\text { Contextual: In the past, Steve wanted to meet his } \\
\text { father's expectations about his student role. Think- } \\
\text { ing of leaving school to travel. Due to developmental } \\
\text { status, peer group was very important to Steve. A } \\
\text { tertiary role assumed the importance of a secondary } \\
\text { role. A political-social group was nationally recog- } \\
\text { nized. Steve wanted to contribute to the mission of } \\
\text { this organization at a national level which influences } \\
\text { legislation. Steve has had doors slammed in his face } \\
\text { when he sought out donations. He felt insecure } \\
\text { about acceptance in this group if his quota was not } \\
\text { met. } \\
\text { Residual: Crisis of "who I will be and who I have been" } \\
\text { has not been resolved so that young adulthood } \\
\text { tasks can begin. }\end{array}$ \\
\hline
\end{tabular}

Table 3

Second-Level Assessment

\begin{tabular}{lc}
\hline \multicolumn{1}{c}{ Interdependence Mode } & \multicolumn{1}{c}{ Influencing Stimuli } \\
\hline $\begin{array}{l}\text { When discussing his situation Steve's face appeared } \\
\text { expressionless; shoulders flexed and eyes gazed } \\
\text { downward most of the time. }\end{array}$ & $\begin{array}{l}\text { Focal: I might not be successful in my peer } \\
\text { group activities. } \\
\text { Contextual: Received and gave ongoing } \\
\text { support in relationship with his sister } \\
\text { Jennifer. But an important source of } \\
\text { support from peers might diminish. } \\
\text { Residual: Will nurturance ability of father } \\
\text { and mother be consistent since there } \\
\text { may be possible marital problems? Reli- } \\
\text { gious beliefs, meaning, and/or restric- } \\
\text { tions regarding possible parental sepa- } \\
\text { ration are unknown. }\end{array}$ \\
\hline
\end{tabular}

peer group which had somewhat of an ideal world view. His intense involvement in his peer group was consistent with adolescent developmental tasks, but it had been at the expense of his education and career goals. Steve was feeling inadequate, but asking for help was developmentally difficult when one was trying to be independent. Although at a low point in parentchild relationship, consistent, loving, and supportive parents are important; and Steve did not have complete confidence about future parental nurturing. Possible nursing diagnoses were low self-esteem (self-concept mode) related to possible loss of social support (interdependence mode), and role failure and conflict (role performance mode) related to adolescent developmental tasks. A nursing diagnosis supporting a strength was: adequate love and respect with Jennifer and parents related to interdependence adaptation.

\section{Adaptive potential assessment model}

A nurse using the adaptive potential assessment model within the modeling and role modeling approach (Erickson, Tomlin, \& Swain, 1988) emphasizes a client's ability to mobilize resources needed to contend with the stress response or the possible stressor-stress relationships among the subsystems. Subjective data regarding stressors, distressors, and need deficits are addressed by modeling a client's world. Modeling includes understanding the client's model (view) of the world and has several steps identified as data collection, data analysis, and diagnosis. Role-modeling means helping individuals redesign their role(s) by assisting them in developing a healthier role in the world and includes planning and intervention. Data are collected for assessment using four categories: description of the situation, immediate and long term expectations, internal and external resources, and current and planned goals. The client is the primary source of information; secondary sources are families, significant others, and the nurse; tertiary sources are all other health care providers. A paragraph of data from primary, secondary, and tertiary sources in each of the four categories is usually collected; but this presentation is limited to only the primary and secondary (nurse) sources. Data are interpreted and then analyzed within the philosophical and theoretical propositions set forth 
in the above publication. Special emphasis is placed on determining the client's strengths, virtues, and available internal resources. Important theory bases include stressor-stresscoping responses (Engel, 1962, 1968; Lazarus 1966; Selye, 1976), basic and growth needs (Maslow, 1968, 1970); developmental processes (Erikson, 1963, 1982), and object attachment (Bowlby 1981; Mahler, 1967).

\section{Description of the situation}

Steve's job with the political-social group was not going well. He had not met his quota in the past and had another three weeks to meet it. Steve viewed this situation as "really bad for me and the group." He had been spending a lot of time with his friends in this group because he believed in their national goals and he enjoyed their friendship. Steve believed "he's not forceful and bold enough with his statements." He perceived a threat of loss of status as an accepted group member if he did not meet his quota. Secondary data, considering Steve's developmental status, meant loss of peer support was a distressor. Another potential loss of support was from his father. Steve's father expected him to graduate from the same midwestern university as he did. Previously, Steve had thought this was what he wanted, too; but now he was not sure. He believed his father would be very disappointed in him if he did not graduate from the same university. Furthermore, consistent support from his parents might be altered given their potential marital problems. Steve self-reported feelings of anxiousness about his midterm exams. During the interview with the nurse, Steve described a recent onset of faintness, gas, frequent urination, and increased sleep that did not refresh him. Secondary data assessment was that Steve had described another possible distressor, a threat of loss of his father's respect and parental nurturance. The two psychosocial distressors which have been identified are beginning evidence of a maladaptive response where psychosocial resources are depleted and physical resources are used to contend with the psychosocial distressors. Steve was experiencing ongoing tenseness-anxiousness regarding threats to basic need satisfaction of belonging. Developmentally, belonging needs are met primarily through peer group association with parents being less important.

\section{Expectations}

Steve was very unsure about his future. He may decide to "take off school next year to work in Montana or California. ... And then go over to Europe for a year or so. Check that out and see how it goes. . . . Then l'd like to come back here to school, but it's not for sure." He planned to change the focus of his studies from sciences to English for which he stated, "I don't see the practical use of it (sciences)." In the past he had viewed himself as an excellent student and a worthwhile person who was expected to graduate from the university that his father had.

\section{Resource potential}

Steve stated that he knew his father would be disappointed in him if he did not continue on with his studies but he explained, "I'm pretty down on school. I'm just ground into the ground. I'm sick of studying and sick of examinations and things like that." Steve stated his relationship with Jennifer was the only thing that "keeps me going." However, he had felt less and less interested in school. He could not remember when his interest seemed to change, but he knew the past semester had not been the same as his first year at the university which he described as "really neat," but no accompanying facial smiles appeared. In fact, secondary analysis revealed conservative-withdrawal posture (Engel, 1962) with shoulders flexed, infrequent eye contact, and a gaze focused downward. Facial expressions were absent as he talked. A fatigued appearance was evident as he described his perception of too much school work and a decreased ability to jog his usual 4 miles. Further secondary data included: Steve most probably had progressed through Erikson's stages of development to identity versus role diffusion with possible past strengths of drive (trust versus mistrust); self-control (autonomy versus self-doubt); direction (initiative versus guilt); and competence (industry versus inferiority) indicated, in part, by his status at a world class university. It seemed possible that Steve had developed many resources in his cognitive subsystem but had not been able to draw upon these resources for use in his psychosocial subsystem. One unanswered question was to what extent did Steve have a strong, positive balance of the first Eriksonian crisis regarding trust versus mistrust, which promotes secure attachment with accompanying attributes of hope and drive. He may have received conditional acceptance from his parents. This means that there is an overt or unspoken message that one is valued (loved, accepted) on the condition that one is doing well in school. Unconditional acceptance means one is valued regardless of one's performance. Anxious attachment to parents (and others) may result from unconditional acceptance which results in constantly having to demonstrate one's worth through excellent performance. In contrast to behavior motivated by basic needs of love and belonging is behavior that is motivated by growth needs (Maslow, 1968,1970 ).

\section{Goals}

Steve's planned goals were uncertain, which could easily be related to the developmental tasks of seeking out an identity in the world. He might leave school to travel and work, he did not know his major in college, and he was unsure about how his peers viewed him and possibly unsure of continued nurturance from his parents. Chronologically, Steve was entering young adulthood, but intimacy did not seem to be a goal for him. Steve was still very much involved with adolescent tasks and goals.

Steve expressed feelings of tenseness-anxiousness regarding basic needs of belonging and 
self-esteem which are very important developmentally to one who is primarily concerned with issues of identity and independence. At least two ongoing distressors were identified as a result of perceived threat of loss of support and respect from peers and parents. Steve's uncertainty about the future was evident, and he appeared to demonstrate a conservative-withdrawal bodily response with accompanying fatigue. The pattern suggested an impoverished state where basic needs are perceived to be unmet and an individual is unable to mobilize coping resources to contend with stressors. In Steve's case, distressors had depleted psychosocial resources, and he was drawing energy from physiological resources, which was evidenced by gastrointestinal genitourinary disturbances, faintness, a somewhat elevated pulse pressure, and increased sleep without feeling refreshed. Possible nursing diagnoses were: impoverishment related to ongoing distressors of loss of support and respect from peers and parents, and unresolved tasks of identity versus role diffusion related to perceived unmet basic needs of belonging and selfesteem. A positive nursing diagnosis was: adequate unconditional acceptance received from Jennifer related to basic need satisfaction.

\section{Evaluation of the Two Assessment Techniques}

An important reminder is that, within this presentation, only portions of each theory have been used due to space constraints. It should be noted that although adaptation accounts for the central theme in the Roy model, the APAM represents only one component of the theory entitled modeling and role-modeling. Both approaches use adaptation as an assessment strategy and comparing the two is important for the reasons cited earlier by Whall (1989).

Extensive work regarding evaluation of conceptual models related to metaparadigm concepts of environment, health, person, and nursing are discussed elsewhere for Roy's model (Fawcett, 1984). Similar metaparadigm concepts are found in the literature for the APAM within the modeling and role-modeling framework (Erickson, Tomlin, \& Swain, 1983; Marriner, 1986). The intent of this presentation is not to repeat earlier efforts but to identify noteworthy areas in nursing science as well as gaps in knowledge by comparing the models. Several criteria were identified to evaluate the assessment techniques. Examinations and judgments were based on: (a) comprehensiveness-completeness and inclusiveness regarding life span concepts; (b) structure - how the parts of the model related to each other including the overall construction; (c) outcome-how the model assisted in stating nursing diagnoses.

\section{Comprehensiveness}

Both approaches have the strength of drawing upon a broad range of theorists and synthesizing a unique nursing perspective from the literature. An important commonality is that individuals are viewed across the life span in particular ways. In this regard, brief examples of comprehensiveness are presented. Models developed by Roy, and Erickson and Swain, have an important similar theoretical base in their use of developmental tasks (Erikson, 1963). Adaptation is considered within the life span concept which, in turn, guides assessment. In addition to developmental status, both models consider human needs approach across the life span. Roy (1987) mentions that the concept of human needs is a part of the Roy model which is yet to be developed. However, some important work has been accomplished in this area. Roy (1984, p. 31.1) aligned the several adaptive modes with human basic needs (Maslow, 1970). Recently, human basic needs have been identified under the four adaptive modes as concepts of physiological integrity, psychic (self-concept) integrity, affectional (interdependence) adequacy, and social (role function) integrity (Andrews \& Roy, 1986). These recently identified concepts are consistent with Roy's initial alignment of adaptive modes (physiological, self-concept, role function, interdependence), with Maslow (1970). Identifying the usefulness of these two theories across the life span facilitates a holistic approach which can best be discussed under the next heading.

\section{Structure}

The two theory bases, developmental status and human needs, are essential to understanding how subsystems of a person interact in a holistic way. For example, when assessing adaptation to stress, developmental level can influence basic need satisfaction, including how physiological and psychosocial needs are met by the individual. It appears that both approaches value this propositional linkage. The difference between the two approaches is that the APAM guides the nurse in assessing the client holistically by the introduction of several concepts. Identification of three concepts, stressors, distressors, and maladaptive responses, seems to be an important feature in this regard. The difference is especially true in the function of physiological data within each model. In the APAM, physiological data are an inherent part of the assessment. The APAM integrates biophysical-psychosocial phenomena to empirically establish the individual's potential for mobilizing adaptive resources. Patterns of biophysical and psychosocial variables determine the classification of adaptive potential. Results of several studies 
(Barnfather, 1987; Barnfather, Swain, \& Erickson, 1989; Erickson, 1976; Erickson \& Swain, 1982) suggest that the patterned variables identified as feelings of tenseness-anxiousness, sadness-depression, fatigue, hope, verbal anxiety, as well as autonomic signs and sensorimotor behavior, are important determinants in viewing clients holistically. Biophysical and psychosocial phenomena are clearly integrated regarding individual's differential potential for mobilizing adaptive resources. In the Roy adaptation model the holistic concept is present but does not come through as a strong contributor in assessment of the client. The model seems weak with respect to integration of the adaptive modes with each other. By and large, assessment strategies remain within the four adaptive modes even though this approach suggests that nursing diagnoses cut across the modes (Andrews \& Roy, 1986; Roy, 1984). Beginning integration is evident in the nursing diagnosis "low self-esteem related to possible loss of social support."

In the overall construction of the two models, there is a divergence between the two approaches. The Roy model gives much more structure for data collection and assessment including priority setting (Roy, 1970, 1984). An advantage to this structured approach is that the Roy model reveals areas where further data collection is needed. For example, residual stimuli provides the nurse with a systematic way to find out what data are missing. This was especially evident under interdependence for religious beliefs.

\section{Outcome}

Both models had considerable influence in guiding and assisting with the statement of nursing diagnoses. To some extent the nursing diagnoses from both models addressed similar content areas. Thus, important domains of nursing practice and nursing knowledge are identified by both models. It should be noted that the APAM appears to expand upon nursing knowledge. The APAM provides evidence to support the adaptive potential of the client whereas the Roy model does not clearly address this issue. The impoverished state of the client means he was unable to mobilize coping resources to contend with ongoing distressors. Specifically, Steve perceived he had depleted his psychosocial resources and was taxing his physiological subsystem to contend with these distressors. It appears that an area where further development in nursing knowledge is needed relates to understanding more about adaptive potential status which elicits information about ability to respond to stressors. In other words, what can an individual reasonably do or be expected to do when contending with stressors?
The concurring parts of the two assessment techniques regarding adaptation to stress that were examined help to identify important domains of nursing science. Several interesting findings became clear, one of which is a similar propositional linkage between developmental level and basic need status. Furthermore, nurses using these two assessment strategies can refer to the above differences between the two models to become aware of important areas for further development of nursing knowledge within each method.

\section{References}

Andrews, H. A., \& Roy, C. (1986). Essentials of the Roy Adaptation Model. Norwalk, CT: Appleton-CenturyCrofts.

Barnfather, J. S. (1987). Mobilizing coping resources related to basic need status in healthy, young adults. Dissertation Abstracts. International, 49, 02-B. 0306. (University Microfilms No. AAD 88-01275)

Barnfather, J. S., Swain, M. A. P. \& Erickson, H. C. (1989). Construct validity of an aspect of the coping process: Potential adaptation to stress. Issues in Mental Health Nursing. 10, 23-40.

Bowlby, J. (1981). Loss. New York: Basic Books.

Brody, S. (1980). Transitional objects: Idealization of a phenomena. Psychoanalytic Quarterly, 49, 563-603.

Coombs, A., \& Syngg, D. (1959). Individual behavior-A perceptual approach to behavior. New York: Harper \& Row.

Cooley, C. H. (1902). Human nature and the social order. Glencoe, IL: Free Press.

Engel, G. (1962). Anxiety and depression-withdrawal. International Journal of Psychoanalysis, 43, 82-97.

Engel, G. (1968). A life setting conductive to illness: The giving-up-given-up complex. Annals of Internal Medicine, 69, 293-300.

Epstein. S. (1973). The self-concept revisited or a theory of a theory. American Psychologist. 28. 404-416.

Erickson, H. (1976). Identification of states of coping utilizing physiological and psychological data. Unpublished masters thesis, The University of Michigan, Ann Arbor, MI.

Erickson, H. C., \& Swain. M. A. P. (1982). A model for assessing potential adaptation to stress. Research in Nursing and Health, 5, 93-101.

Erickson, H. C., Tomlin, E., \& Swain, M. A. P. (1988). Modeling and role-modeling: A theory and paradigm for nursing. Lexington, SC: Est, Pine Press of Lexington.

Erikson. E. H. (1963). Childhood and society (2nd Ed.). New York: W. W. Norton.

Erikson, E. H. (1982). The cycle of life. New York: W. W. Norton.

Fawcett, J. (1984). Analysis and evaluation of conceptual models of nursing. Philadelphia: F. A. Davis.

Fromm, E. (1956). The art of loving. New York: Harper \& Row.

Galligan, A. C. (1979). Using Roy's concept of adaptation. The American Journal of Maternal Child Nursing, 4. 24-28.

Gardner, B. D. (1964). Development in early childhood. New York: Harper \& Row.

Goffman, E. (1961). Encounters. Indianapolis: BobbsMerrill.

Havighurst. R. T. (1953). Human development and education. New York: Longmans. Green.

Lazarus, R. S. (1966). Psychological stress and the coping process. New York: McGraw-Hill.

Lyon, B. \& Werner, J. (1987). Stress. In J. J. Fitzpatrick \& R. L. Taunton (Eds.). Annual Review of Nursing Research, 5, 3-22.

Mahler, M. S. (1967). On human symbosis and the vissi- 